\title{
Business logistics and logistics engineering: the rocky road to a unified science of logistics
}

Peter Klaus

Published online: 7 April 2010

(C) Springer-Verlag 2010

A "science of logistics": Is there any? And if so, is there one-or two, or even several? To answer these questions is not easy. We know that different members of the large worldwide logistics community (which certainly does exist) would have very different views.

When we started this journal, one of our assumptions was that definitely there should be a unified "science of logistics"! We made the integration of research and theory developments in the fields of business logistics and logistics engineering one of the key aims of our editorial work. And we strongly believe that the vision of an integrated field - where different ways of thinking, different experiences and methods are meeting to stimulate creativity-is right. It promises to expand the range, perspectives and options available for the solution of pressing real-world problems in the economy. And, last not least, it distinguishes our journal from others.

But we also learn that it is not easy to make this work at the level of hands-on editorial work: Some submissions of articles are covering research issues at a level so deep inside their respective specialty that they will not be understood outside. We found that the criteria applied by reviewers with very different kinds of disciplinary backgrounds will often lead to extremely divergent judgements on articles submitted. It is challenging to motivate authors from the different backgrounds to submit manuscripts in numbers that allow for an acceptable balance of those papers. This is a problem especially in those countries where the activities and definitions of logistics have been restricted to the "business logistics" aspects in the past.

P. Klaus $(\square)$

University of Erlangen-Nürnberg, Nuremberg, Germany

e-mail: peter.klaus@wiso.uni-erlangen.de

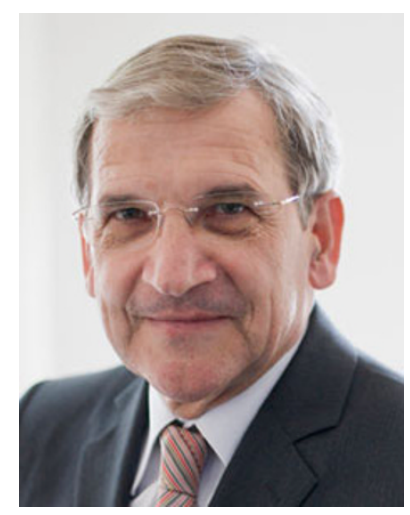

The realization of the vision of a unified "science of logistics" may still need a lot of time. We are all the more pleased that in this issue of five original articles we have the kind of cross-section and balance that we are looking for over the longer term: there are two which represent the "engineering" side of logistics (i.e. Meissner's prize-winning paper on "Controlling just-in-sequence flow-production" and Weichert's "Marker-based tracking in support of RFID controlled material flow systems"), two which address issues in "business logistics" (Pfohl/Gomm's timely review and assessment of the "State of the art in supply chain risk management research" and Liu/McKinnon/Grant/Feng's study on "Sources of Competitiveness for Logistics Service Providers"). Last but not least there is Drexl's "operations research" based work on "Labelling algorithms for the elementary shortest path problem with resource constraints considering EU drivers' rules".

We hope you will find these papers a good selection!

Looking ahead: In one of our upcoming issues, we will present results of an ambitious project by members of BVL's Scientific Advisory Board. They are currently developing a statement of "logistics as a field of science". We are also preparing for a call-for-papers on issues of "autonomous controls" and governance in complex logistics systems.

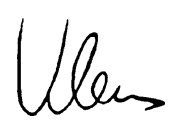

Peter Klaus, Editor-in-Chief LOGISTICS RESEARCH March 2010 